\title{
Tuber cinereum lipoma
}

Dear Sir,

Intracranial lipomas are congenital malformations commonly located in the midline cerebral structures. They account for less than $1 \%$ of intracranial tumours. ${ }^{1}$

A 39 year old female presented to the Surgery department with left lower limb cellulitis, extending from the ankle to just below the knee joint. She was a diabetic, on insulin therapy for the past 1 year. She was conscious, oriented and febrile $\left(100^{\circ} \mathrm{F}\right)$, with stable vitals and normal systemic examinations. Her blood investigations showed leucocytosis (13000 cells/cumm with neutrophils $90 \%$ and lymphocytes $10 \%$ ) and HbA1c of $7.2 \%$. Other routine investigations were normal. She was treated with intravenous Piperacillin/Tazobactum (4.5gram q6h) and improved within 3 days. During her hospital stay, she had 3 episodes of headache, which was throbbing in nature, generalised, lasting about 4 to 5 hours, associated with nausea and aggravated with head movements. There were no other neurological symptoms. She has been having similar episodes for the past 8 years and was told to have migraine; and her symptoms used to subside with paracetamol. Magnetic resonance imaging (MRI) of the brain was suggestive of tuber cinereum lipoma measuring 10x4 mm (Figures 1 and 2). She was managed with propranolol, paracetamol and domperidone; following which she improved. Following discharge she had only 2 to 3 episodes of headache over the next 3 months; which were mild in terms of severity. Repeat MRI brain after 3 months did not show any increase in size of the lipoma. She was advised regular follow ups.

Intracranial lipomas may be considered as an incomplete benign mesenchymoma consisting of inclusion of embryonal germs of primitive meninx into the nervous system. This event may occur early during the third month of intrauterine life, when the primitive septa are being formed. They may be associated with brain malformations like cerebral vascular defects, agenesis of the surrounding tissues, frontal bone defects or facial dysplasia. ${ }^{1}$ Headache, seizures and cranial nerve deficits are the presenting complaints. Some of the cases are diagnosed incidentally

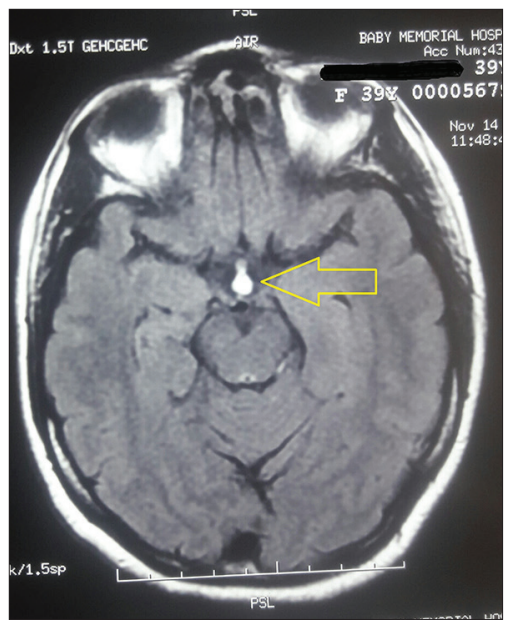

Figure 1: MRI brain (axial view) showing tuber cinereum lipoma

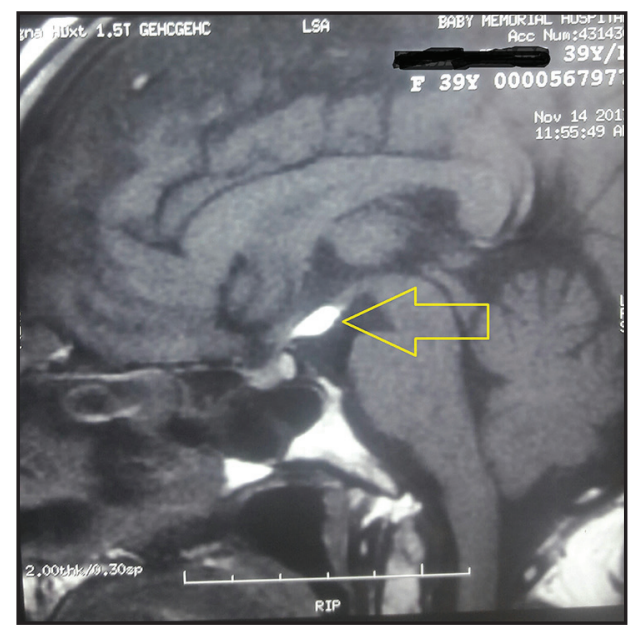

Figure 2: MRI brain (saggital view) showing tuber cinereum lipoma

during brain imaging for other reasons like trauma. These patients are managed symptomatically. The prognosis is good and surgical approach is reserved for patients with severe symptoms or those with associated malformations. 
Only a handful of cases of tuber cinereum lipoma have been reported; and most of them were incidental findings on autopsy, while some had neurological symptoms requiring surgical intervention. ${ }^{2,3}$

Key words: Intracranial lipomas, Tuber cinereum, Intracranial tumours

\section{Robin George Manappallil' ${ }^{1}$, Pradeep Kumar VG², Chinganthara Cleetus Suresh ${ }^{3}$}

${ }^{1}$ Consultant, Department of Internal Medicine, Senior Consultant, Departments of ${ }^{2}$ Neurology and ${ }^{3}$ General Surgery, Baby Memorial Hospital, Calicut, Kerala, India
Address for correspondence: Dr. Robin George Manappallil, Consultant- Physician, Department of Internal Medicine, Baby Memorial Hospital, Calicut 673004, Kerala, India. Mobile: +91-8547753396. E-mail: drrobingeorgempl@gmail.com

\section{REFERENCES}

1. Discepoli S. The lipoma of tuber cinereum. Tumori 1980; 66(1):123-130

2. Kalakoti P, Ahmed O, Jacobsohn JA and Nanda A. Symptomatic osteolipoma of the tuber cinereum masquerading as calcified retroclival mass. J Clin Neurosci 2015; 22(6):1045-1051.

3. Bognár L, Bálint $\mathrm{K}$ and Bárdóczy Z. Symptomatic osteolipoma of the tuber cinereum. Case report. J Neurosurg 2002; 96(2):361-363.

\section{Authors Contribution:}

RGM- Reviewed the literature, manuscript preparation and treating Physician; PKVG- Concept and design of case report and treating Neurologist; CCS- Critical revision of manuscript and treating Surgeon.

Orcid ID:

Dr. Robin George Manappallil - (1) http://orcid.org/0000-0003-3973-6800

Source of Support: Nil, Conflict of Interest: None declared. 